\title{
The genetic status of mothers of isolated cases of Duchenne muscular dystrophy
}

\author{
RUSSELL J M LANE*, MEINHARD ROBINOW $\dagger_{+}^{+}$, AND ALLEN D ROSES* \\ From *the Division of Neurology, Department of Medicine, Duke University Medical Center, Durham, \\ North Carolina; and $\dagger$ the Department of Pediatrics, University of Virginia, Charlottesville, Virginia, USA.
}

SUMMARY Classical genetic theory, ${ }^{1}$ based on assumed equal mutation rates in males and females, predicts that one-third of all cases of Duchenne muscular dystrophy (DMD) in a generation are born as new mutants to non-carrier mothers. Furthermore, less than half the mothers of apparently isolated cases appear to be carriers on the basis of raised serum creatine kinase levels. ${ }^{2}$

We have analysed the pedigrees of 61 families of DMD boys seen in the Duke Neuromuscular Research Clinic and 45 DMD families followed at the University of Virginia.

The frequency of affected boys among the next born male sibs of 37 initially isolated DMD cases in two clinic populations was significantly greater than predicted by Haldane's theory ${ }^{1}(p=0 \cdot 029)$ and the estimated proportion of new mutant cases in the combined clinic population of 106 families was $0 \cdot 127(\mathrm{SE} 0 \cdot 111)$.

The absence of affected males in earlier generations in families of isolated cases may be explained in part by a high ratio of male to female stillbirths and infant deaths, which was more than three times that of the normal population in this study. These data suggest that new mutant cases are less common than expected and current predictions may underestimate genetic risks in mothers of isolated cases.

When the mother of a boy with Duchenne muscular dystrophy (DMD) is an obligate heterozygote, the genetic risks in future pregnancies are clearly defined: a future son has a $50 \%$ chance of being affected and any daughter has a $50 \%$ chance of being a carrier. In early population studies, between one-quarter and one-half of all ascertained cases were born to mothers with a family history of the disease (table 1). New familial cases are now seen much less frequently and apparently isolated cases now constitute the great majority of referrals.

In the absence of a definitive test for the carrier state, we cannot determine with certainty whether the mother of an isolated case is a heterozygote or if the disease resulted from a new mutation. The genetic status of the mother can only be inferred from probability calculations which incorporate genetic and biochemical data, ${ }^{19-21}$ such as the relative probability of the mother's serum creatine kinase (CK) level occurring in a heterozygote or normal female, with an assumed prior risk of heterozygosity.

$\ddagger$ Present address: Department of Dysmorphology, Children’s Medical Center, Dayton, Ohio 45404, USA.

Received for publication 29 July 1982
This prior risk is based on the work of Haldane ${ }^{1}$ who showed that, in an $\mathrm{X}$ linked disorder where genetic equilibrium is maintained by mutation alone, the proportion of new mutant cases born to non-carrier mothers is (1-f) $\mu /(2 \mu+\nu)$, where $\mu$ is the mutation rate in female germ cells, $\nu$ the mutation rate in male germ cells, and $f$ the reproductive fitness of affected persons. In DMD, $f$ is effectively 0 and the proportion of new mutants thus depends on the ratio of the mutation rates in the sexes. If the male and female mutation rates are equal, one-third of all cases born in a generation must be new mutants.

Analyses of some earlier DMD population studies $^{22-24}$ supported this theory and were corroborated by later studies based on the frequency of raised CK levels in mothers of affected boys. ${ }^{2} 112526$ Accordingly, an initial two-thirds prior genetic risk of carrier status is often assigned to the mother of an isolated case. ${ }^{27}$ However, in two other $X$ linked diseases where specific biochemical identification of heterozygotes is now possible, haemophilia $\mathbf{A}$ and Lesch-Nyhan syndrome, the proportion of new mutant cases in some studies was far lower than expected. ${ }^{28-32}$ The results of pedigree testing from our clinic ${ }^{3334}$ and others, ${ }^{35-38}$ using a variety of 
TABLE 1 Population studies in DMD.

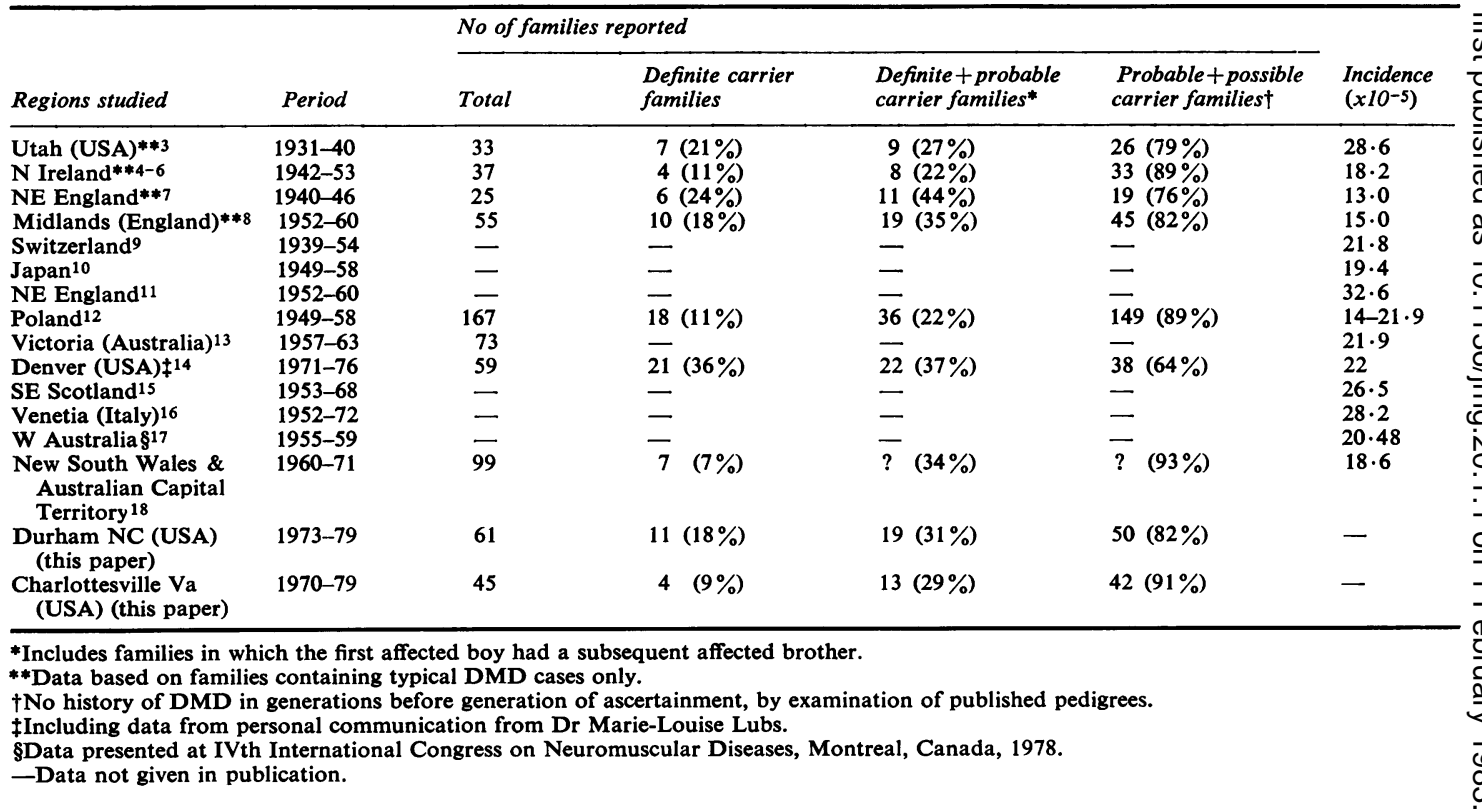

non-specific carrier detection tests in addition to CK, also suggest a paucity of new mutations in DMD (table 2). This implies that genetic equilibrium might be maintained by mechanisms other than new mutations, such as a higher mutation rate in males than females, heterozygote advantage, reproductive compensation, or through a mechanism requiring complementary gene pairs for complete heterozygosity. ${ }^{40}$ Such mechanisms would demand that many more mothers of apparently isolated cases were genetic carriers than formerly believed.
In preliminary reports, ${ }^{4142}$ the risk of carrier status in mothers of isolated cases was assessed by observing the sex and segregation ratios in sibs born after the first affected boys in the families followed by the Neuromuscular Diseases Research $\mathbb{2}$ Clinic at Duke University Medical Center. In this study we have extended these observations and have 3 incorporated additional data, independently obtained $\vec{P}$ by the Muscular Dystrophy Clinic at the University? of Virginia, Charlottesville (UVa). Analysis of the combined data from these 106 DMD families

TABLE 2 Estimation of $x$ by segregation analysis and carrier detection.

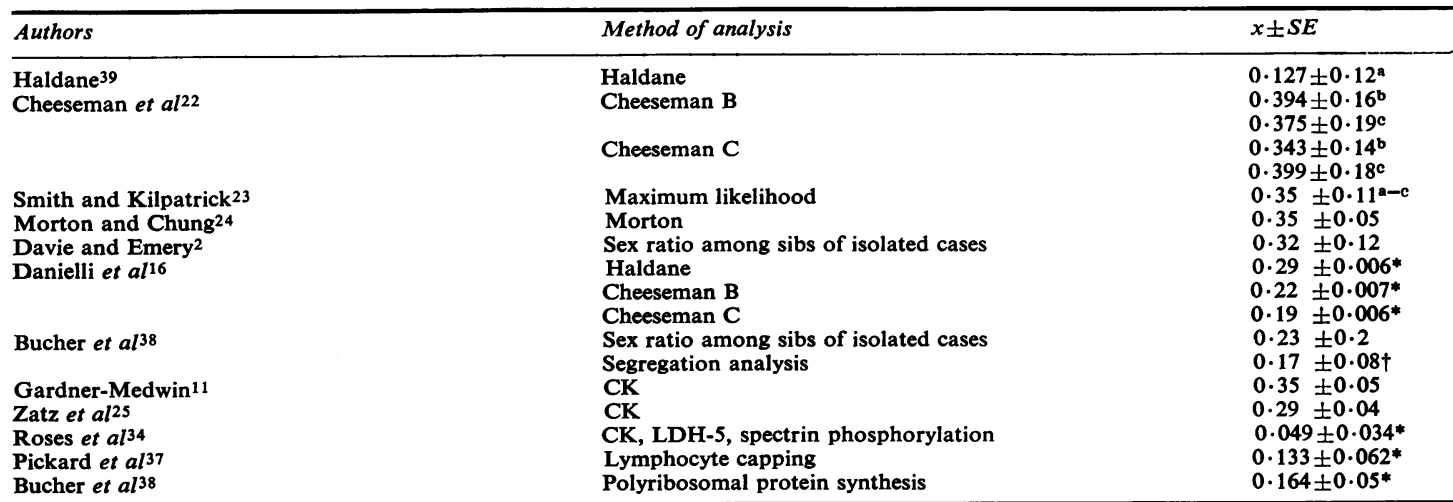

Data from Stevenson ${ }^{4}$ and Walton. ${ }^{7}$

bData from Stevenson. 45

cData from Stephens and Tyler. 3

Significantly less than $0.33 * p<0.01 \dagger p<0.05$. 
suggests that a higher proportion of mothers of isolated DMD cases may be carriers than previously thought.

\section{Patients and methods}

\section{DEFINITIONS}

A definite carrier ${ }^{43}$ or obligate heterozygote is a woman with one or more affected sons and other affected male relatives in the female lineage. Mothers in this category thus have a family history of the disease at the time their first affected son is born.

A possible carrier has only one affected son, no other affected male relatives, and no known family history of the disease in earlier generations. Possible carriers are also frequently referred to as mothers of isolated cases. Such mothers will comprise normal homozygous women, whose affected sons are sporadic (new mutant) cases and true genetic carriers.

A probable carrier ${ }^{43}$ is a woman with two or more affected sons but no other affected male relatives and no known history of the disease in earlier generations. The probability that each affected boy represents an independant mutation is infinitesimal and probable carriers can be considered heterozygotes for counselling purposes. Since the mean age of diagnosis in DMD is about 5 years, these mothers have usually had further affected sons by the time the first affected boy is diagnosed. However, with respect to genetic counselling, we would emphasise that at the time of the birth of the first affected boy such women were also 'mothers of isolated cases'. Only subsequent events revealed their true genetic status. An initially isolated case, for the purpose of our retrospective study, can therefore be defined simply as the first affected boy in a family with no other affected male relatives and no known history of DMD in earlier generations. These families will be referred to as isolated (simplex and multiplex) sibships or fraternities. The situation can be illustrated thus:

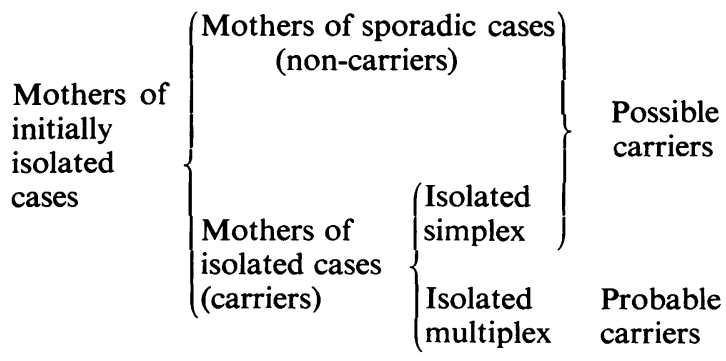

\section{ASCERTAINMENT OF FAMILIES}

The Duke and UVa clinics serve similar catchment areas and have been in operation for about 10 years.
The Duke families were ascertained at a time when the Neuromuscular Research Clinic was engaged almost exclusively in basic research into the biochemical basis of DMD. No formal genetic counselling was offered which might have directly affected subsequent events in these families. The UVa clinic families received genetic counselling, but this was considered relatively ineffective. There was, in fact, no significant difference in the proportions of DMD boys, normal boys, and girls in the two clinic populations $\left(\chi^{2}=1 \cdot 525,2 \mathrm{df}\right)$.

The Duke clinic population comprised 61 families of boys with DMD. In nearly all instances, the families were ascertained directly through the first affected boy and the diagnosis of DMD was made by appropriate clinical, biochemical, and histological examinations. In some cases, diagnosis of the first affected son was made elsewhere and the family was referred secondarily for biochemical studies. The families have been extensively studied. Virtually every female relative has been examined by manual muscle strength testing ${ }^{44}$ and other carrier detection techniques, including measurement of $\mathrm{CK}$ and $\mathrm{CK}$ isoenzymes, $\mathrm{LDH}$ and $\mathrm{LDH}$ isoenzymes, SGOT and SGPT, and ECG analysis. ${ }^{34} 45$ In some families red cell membrane protein band 2 phosphorylation studies have been performed. The results of these investigations have been fully reported previously. ${ }^{33} 344647$

In the present investigation, particular attention was paid to birth order in the pedigrees, and the segregation of sibs born after the first affected boy in the generation of ascertainment was recorded. In addition, all known instances of stillbirth, miscarriage, and early childhood death (under age 5) in the three generations before ascertainment was noted.

The UVa clinic population consisted of 45 DMD families. Again, careful attention was paid to birth order. Many of the females in the pedigrees had been tested by measurement of CK, LDH isoenzymes, SGOT, and SGPT and a high proportion of the mothers had demonstrated abnormal lymphocyte capping. ${ }^{37}$

\section{Results}

COMPOSITION OF CLINIC POPULATIONS

Analyses of pedigrees in earlier published studies, in which complete ascertainment of affected cases in defined populations was attempted, suggested that 10 to $20 \%$ of mothers of DMD boys had a family history of the disease (that is, were definite carriers) at the time of birth of the first affected son in the generation of ascertainment (table 1). The proportions of familial and initially isolated cases in our pedigrees were comparable to those reported in these earlier studies (table 1). 
TABLE 3a Duchenne dystrophy families: Duke series.

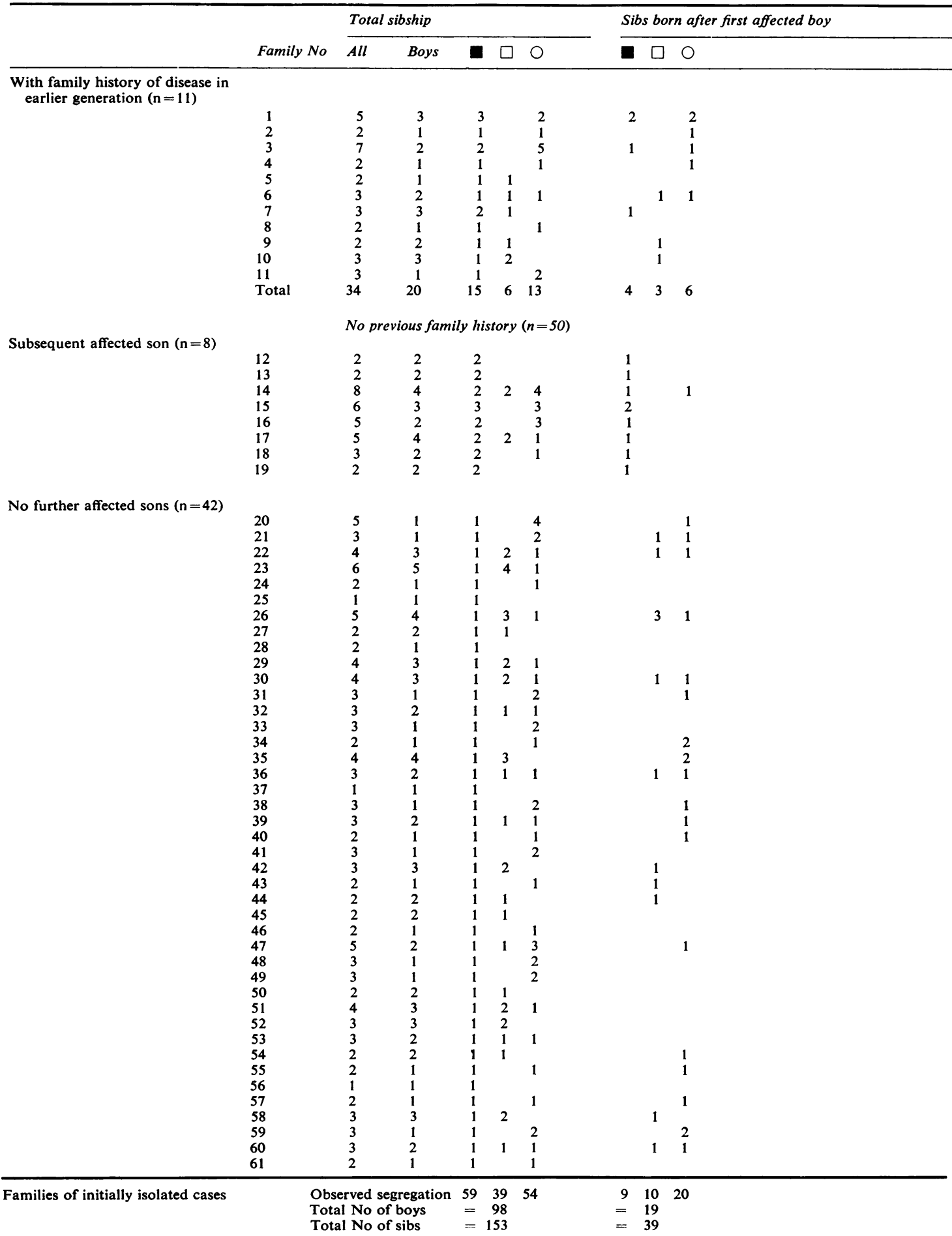


Tables $3 a$ and $b$ give details of sibships in the generation of ascertainment in the Duke and UVa clinics, respectively. Tables $4 \mathrm{a}$ and $\mathrm{b}$ show the overall segregations in the families, both for the total sibships and for sibs born after the first affected boy. In the Duke series, 11 of the 61 families $(18 \%)$ had a history of DMD in earlier generations at the time of ascertainment, while in the remaining 50 families the first affected boys were initially isolated cases. In the UVa series, four mothers were definite carriers $(9 \%)$ and 41 were mothers of initially isolated cases. Subsequently, a similar number of mothers (eight in the Duke series and nine in the UVa group) had further affected sons (isolated multiplex sibships). Family 8 in the UVa series was very unusual. The mother, who had a normal creatine kinase level, had three normal brothers (and thus a very low prior probability of being a carrier) but all her six sons were affected.

TABLE 3b Duchenne dystrophy families: Charlottesville series.

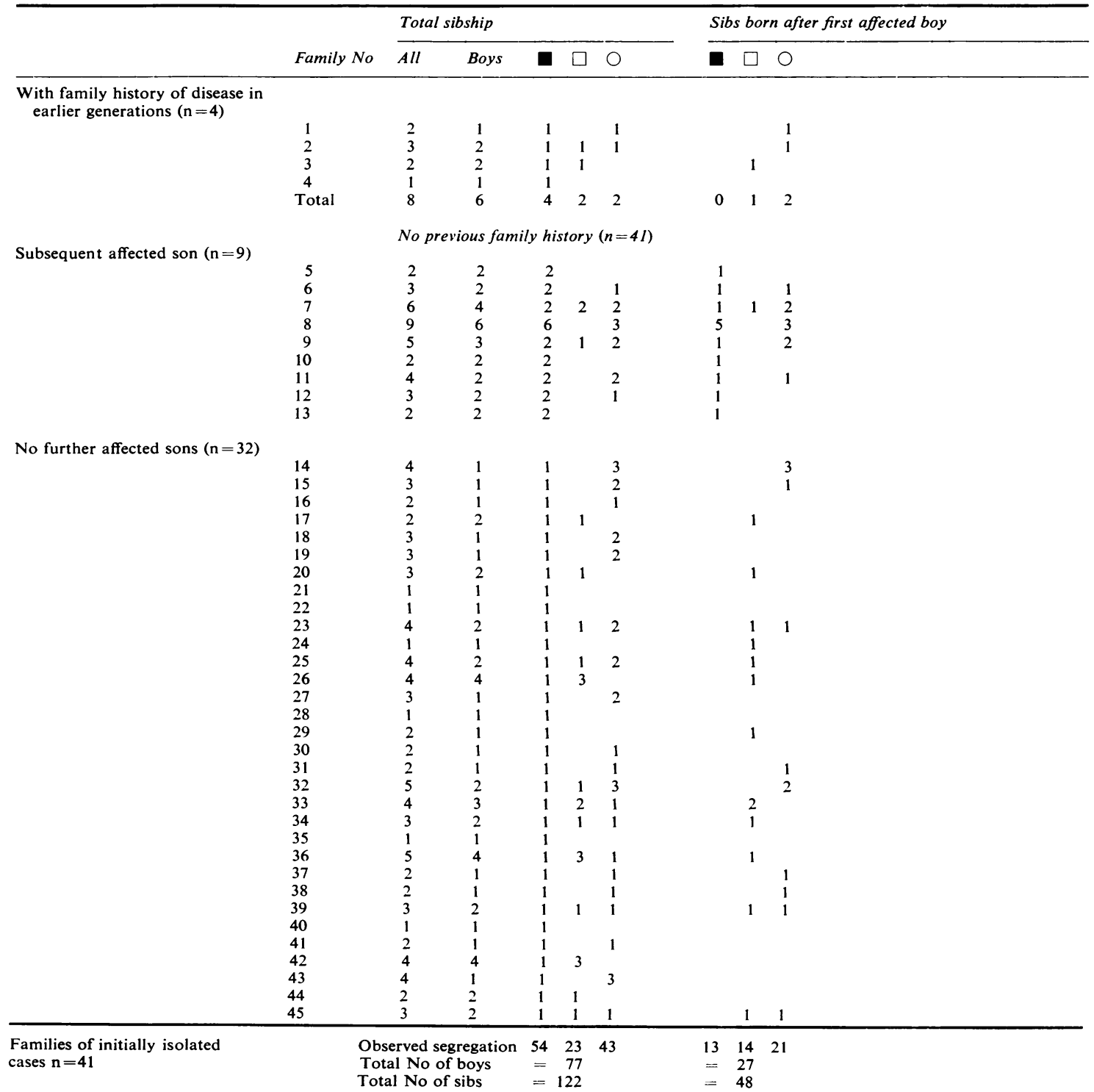


SEGREGATION ANALYSIS

Subsequent sibs method

We examined the segregation of DMD boys, normal boys, and girls born after the first affected boy in families of initially isolated cases. This method is pertinent to the commonest problem in genetic counselling in DMD, which is assessment of the risk of a further affected boy being born to the mother of an apparently isolated case.

If there are $r$ initially isolated cases in s sibships, Haldane's theory predicts that the number of new mutant cases will be $\geqslant r / 3$. Thus, the number of carrier mothers will be $\leqslant s-r / 3$ and the proportion of carrier mothers $m_{c} \leqslant(s-r / 3) / s$.

For the Duke clinic families (table $4 a$ ), $s=50$, $r=59$; for the UVa clinic (table $4 b$ ), $s=41$, $r=54$. The expected proportions of carriers $\left(m_{c}\right)$ are respectively $0.6,0.56$, and for the combined data $0 \cdot 58$. (These calculated values for $m_{c}$ will in fact be an overestimate.)

If $\mathrm{n}$ sibs are born after the first affected boy, assuming equal fertility in carriers and non-carriers, the expected segregation is $\mathrm{nm}_{\mathrm{c}} / 4$ DMD boys, $\left(n\left(2-m_{c}\right)\right) / 4$ normal boys, $n / 2$ girls. If all mothers are carriers, the expected segregation is $\mathrm{n} / 4 \mathrm{DMD}$ boys, $n / 4$ normal boys, $n / 2$ girls. The proportion of girls in either case is identical and subsequent analysis can be confined to brothers of affected boys.

Bias can be limited by examining the incidence of affected and non-affected boys among the next born male sibs in these families. Of the 50 families of initially isolated cases in the Duke series, there were
16 in which a brother was born after the first affected boy and of these eight were affected. In the 41 families of initially isolated cases from UVa there were 21 in which a boy was born after the first DMD boy and of these nine were affected. The expected proportions of DMD boys in the two clinics and the combined population were calculated from $\mathrm{m}_{\mathrm{c}}$ values assuming Haldane's theory. Expected values were also calculated assuming that all mothers were carriers $\left(m_{c}=1 \cdot 0\right)$. The probabilities that the observed proportions did not differ from the calculated values were derived by binomial theorem (table 5). The observed segregation was close to that expected assuming all mothers were carriers, and when the families of initially isolated cases in the two clinics were combined, the frequency of affected boys was significantly greater $(p=0.029)$ than predicted from Haldane's theory assuming equal mutation rates in the sexes.

Estimation of proportion of new mutant cases $(x)$ The proportion of new mutant cases $(x)$ was estimated by the method of Cheeseman et $\mathrm{al}^{22}$ (method B) for each clinic population and for the combined series (tables 6,7 ):

$$
\frac{\mathrm{x}=\Sigma\left(\mathrm{n}_{\mathrm{s}}-\mathrm{m}_{\mathrm{s}}\left(1-\mathrm{p}_{\mathrm{s}}\right)^{-1}\right)}{\Sigma \mathrm{a}_{\mathrm{s}}}
$$

where

$\mathrm{s}=$ fraternity size, $\mathrm{n}_{\mathrm{s}}=$ number of fraternities of $\mathrm{s}$ sons where $\mathrm{s}>1$,

TABLE 4a Sex and segregation ratios in 61 families of boys with DMD, Duke Neuromuscular Disease Clinic, April 1979.

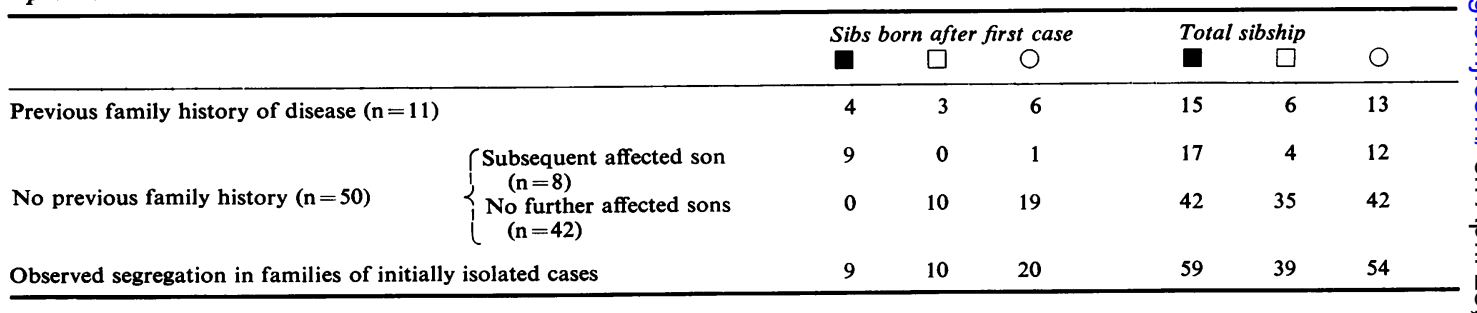

TABLE 4b Sex and segregation ratios in 46 families of boys with DMD, Charlottesville Muscular Dystrophy Clinic, 1979.

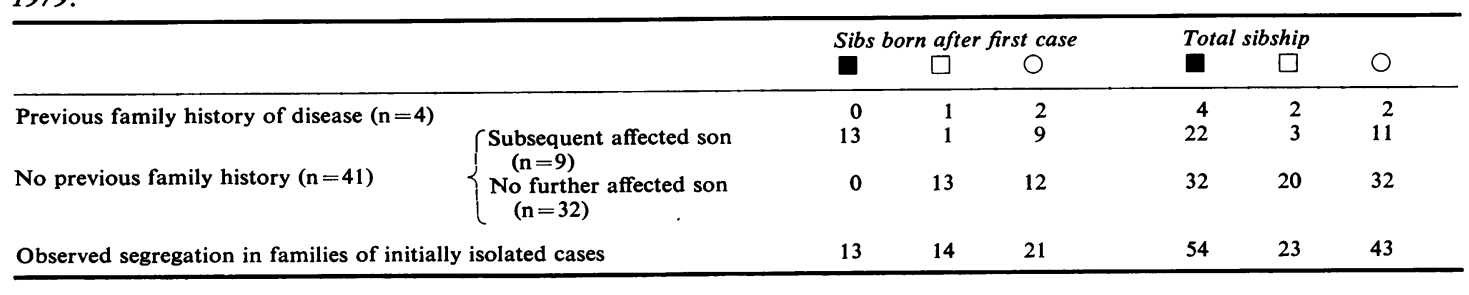


TABLE 5 Segregation among next born male sibs in families of initially isolated cases.

\begin{tabular}{|c|c|c|c|c|c|c|}
\hline & \multirow{2}{*}{$\begin{array}{l}\text { No of families with } \\
\text { subsequent son }\end{array}$} & \multirow[b]{2}{*}{ DMD observed } & \multicolumn{2}{|c|}{$D M D$ expected } & \multicolumn{2}{|c|}{$\begin{array}{l}\text { Probability }(p) \text { that observed proportion } \\
\text { does not differ from expected }\end{array}$} \\
\hline & & & $m_{\mathrm{c}}$ carriers & All carriers & $m_{\mathrm{c}}$ carriers & All carriers \\
\hline $\begin{array}{l}\text { Duke } \\
\qquad\left(\mathrm{m}_{c}=0.6\right)\end{array}$ & 16 & 8 & $4 \cdot 8$ & 8 & 0.1 & 1.0 \\
\hline $\begin{array}{l}\mathrm{UVa} \\
\quad\left(\mathrm{m}_{\mathrm{c}}=0.56\right)\end{array}$ & 21 & 9 & $5 \cdot 9$ & $10 \cdot 5$ & $0 \cdot 15$ & 0.66 \\
\hline $\begin{array}{l}\text { Combined } \\
\qquad\left(m_{c}=0.58\right)\end{array}$ & 37 & 17 & $10 \cdot 73$ & $18 \cdot 5$ & 0.029 & 0.74 \\
\hline
\end{tabular}

TABLE 6 Distribution of fraternities by size (s) and number of affected males (a) in DMD families

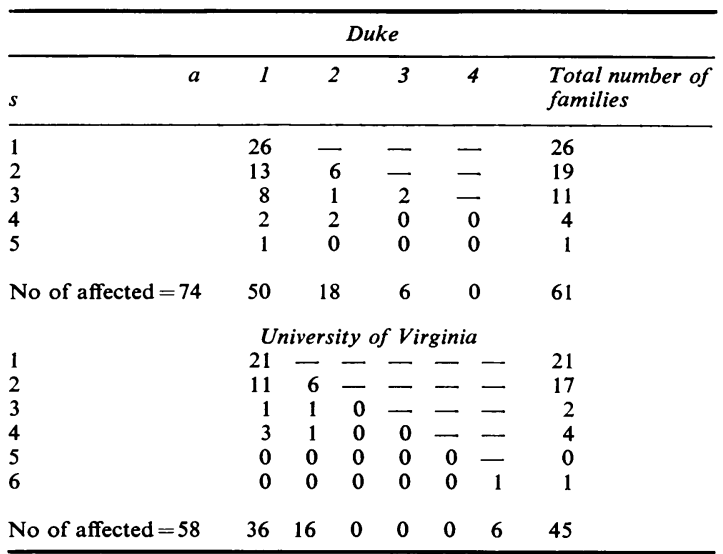

TABLE 7 Calculation of $x$ by method B of Cheesemanet al. ${ }^{22}$

\begin{tabular}{|c|c|c|c|c|}
\hline \multicolumn{5}{|c|}{ Duke $\left(a_{\mathrm{S}}=48\right)$} \\
\hline $\mathbf{s}$ & $\mathrm{p}_{\mathbf{s}}$ & $\mathrm{n}_{\mathbf{S}}$ & $\mathrm{m}_{\mathbf{s}}$ & $\mathrm{n}_{\mathrm{S}}-\mathrm{m}_{\mathrm{s}} /\left(1-\mathrm{p}_{\mathrm{s}}\right)$ \\
\hline 2 & $2 / 3$ & 19 & 6 & 1.000 \\
\hline 3 & $3 / 7$ & 11 & 3 & $5 \cdot 750$ \\
\hline 4 & $4 / 15$ & 4 & 2 & $1 \cdot 273$ \\
\hline 5 & $5 / 31$ & 1 & 0 & 1.000 \\
\hline
\end{tabular}

$\mathrm{x}=0 \cdot 188, \mathrm{SE}=0 \cdot 148(\mathrm{p}=0 \cdot 33)$

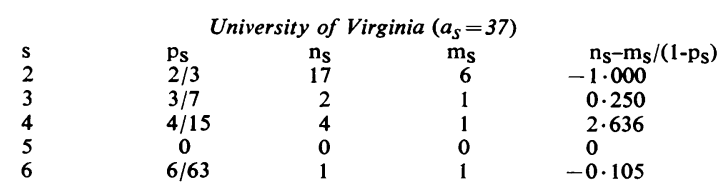

$x=0.048, \mathrm{SE}=0 \cdot 166(\mathrm{p}=0.085)$

\begin{tabular}{llrll}
\multicolumn{5}{c}{ Combined data $\left(a_{s}=85\right)$} \\
$\mathrm{s}$ & $\mathrm{p}_{\mathbf{S}}$ & $\mathrm{n}_{\mathrm{S}}$ & $\mathrm{m}_{\mathrm{s}}$ & $\mathrm{n}_{\mathrm{s}}-\mathrm{m}_{\mathrm{s}} /\left(1-\mathrm{p}_{\mathrm{s}}\right)$ \\
2 & $2 / 3$ & 36 & 12 & $0 \cdot 000$ \\
3 & $3 / 7$ & 13 & 4 & $6 \cdot 000$ \\
4 & $4 / 15$ & 8 & 3 & $3 \cdot 9091$ \\
5 & $5 / 31$ & 1 & 0 & $1 \cdot 000$ \\
6 & $6 / 63$ & 1 & 1 & $0 \cdot 1053$ \\
\hline
\end{tabular}

$x=0 \cdot 127, S E=0 \cdot 111(p=0 \cdot 063)$ $\mathrm{m}_{\mathrm{s}}=$ number of fraternities with more than one affected boy,

$p_{s}=$ probability of observing $a_{s}$ affected persons in fraternity size $s$,

$a_{s}=$ number of affected boys in fraternities of $s>1$ (appendix).

This method is only valid for truncate selection which was not attempted in this study. However, table 1 indicates that the distribution of familial (definite and probable carrier mothers) and nonfamilial cases was similar to earlier studies in which complete ascertainment was attempted and on which currently accepted data on the frequency of mutant cases are based.

The values of $\mathrm{x}$ derived from the Duke and Charlottesville clinic data were $0 \cdot 188$ (SE 0.148) and 0.048 (SE 0.166) respectively, and for the combined clinic population $0 \cdot 127$ (SE $0 \cdot 111$ ), which is less than the expected value of 0.33 at $p=0.063$.

TABLE 8 Stillbirths and deaths under age 5 in 3 generations before ascertainment (Duke series).

\begin{tabular}{|c|c|c|c|c|}
\hline & & Boys & Girls & Ratio \\
\hline \multicolumn{2}{|c|}{$\begin{array}{l}\text { Previous family history of disease } \\
\quad(n=11)\end{array}$} & 6 & 1 & $6 \cdot 0$ \\
\hline No previous & $\left\{\begin{array}{l}\text { Subsequent } \\
\text { affected son } \\
(n=8)\end{array}\right.$ & 6 & 1 & $6 \cdot 0$ \\
\hline $\begin{array}{l}\text { family history } \\
(n=50)\end{array}$ & $\begin{array}{l}\text { No further } \\
\text { affected son } \\
(n=42)\end{array}$ & 28 & 9 & $3 \cdot 1$ \\
\hline
\end{tabular}

Ratio of male to female infant deaths in North Carolina.*

\begin{tabular}{lll}
\hline Year & 1 year & $1-4$ years \\
\hline 1920 & $1 \cdot 24$ & $1 \cdot 13$ \\
1930 & $1 \cdot 23$ & $1 \cdot 11$ \\
1940 & $1 \cdot 3$ & $1 \cdot 1$ \\
1945 & $1 \cdot 37$ & $1 \cdot 18$ \\
1955 & $1 \cdot 33$ & $1 \cdot 18$ \\
1965 & $1 \cdot 32$ & $1 \cdot 26$ \\
1975 & $1 \cdot 41$ & $1 \cdot 3$
\end{tabular}

*Data from Vital Statistics of the United States, 1900-1940 by F E Lindler and R D Grove, and $1940-1960$ by R D Grove and A M Hetzel, and from Vital Statistics of the United States, Vol 2, part B. Department of Health, Education and Welfare, 1975. 
SEX RATIO FOR STILLBIRTHS AND EARLY INFANT DEATHS IN GENERATIONS BEFORE ASCERTAINMENT

Table 8 shows the distribution of infant deaths and stillbirths in the three generations before ascertainment in the 61 families in the Duke series. The incidence of miscarriage is often underestimated and family details in the distant past were naturally often incomplete. However, there was a remarkable preponderance of male to female infant deaths of over $3: 1$ compared to a maximum ratio of $1.41: 1$ in the normal population over the same period.

\section{Discussion}

The central issue in any consideration of genetic counselling in DMD is the proportion of mothers of isolated cases who are genetic carriers and the proportion who are in fact normal homozygotes but have an affected son, a sporadic case, as the result of a new mutation. Analyses of data from earlier published series suggested that the proportion of new mutant cases was close to $0 \cdot 33$, the value expected assuming that genetic equilibrium was maintained by mutation alone and that mutation rates in males and females were equal. ${ }^{222} 24$ Furthermore, Davie and Emery ${ }^{2}$ recently estimated that, based on the proportion of mothers with raised CK levels in several series, only about half (0.49) of mothers of isolated (simplex) cases were heterozygotes.

Although complete ascertainment of cases in a geographical area was attempted in many of these early studies, Brooks and Emery ${ }^{15}$ found significant differences in reported disease incidence, implying incomplete ascertainment which might have resulted in overrepresentation of sporadic cases. ${ }^{28}$ In addition, recent work has suggested that $\mathrm{CK}$ levels may be under independent genetic control. ${ }^{48}$ The frequency of raised CK levels in mothers of affected boys may not be a sufficiently accurate reflection of genetic status on which to base predictions regarding mutation rate; there may be 'low CK' families and 'high CK' families. ${ }^{4950}$

The data presented here suggest that considerably more mothers of DMD boys are genetic carriers than previously thought. The segregation among sibs born after the first affected boys in the two clinic populations was close to the proportions expected assuming all mothers were carriers (tables $4 a, b)$, and the frequency of affected boys among the next born male sibs in the combined clinic population was significantly greater than predicted from Haldane's theory ( $p=0.029$, table 5). Furthermore, the estimated proportion of new mutant cases in the 106 families studied was $0 \cdot 127$, significantly different from 0.33 at $p=0.063$.

Estimates of the proportion of sporadic cases $(x)$ using data from different series have varied considerably (table 2). Cheeseman et $a^{22}$ found $\mathrm{x}$ to be close to 0.33 from the data of Stevenson ${ }^{4}$ and Stephens and Tyler. ${ }^{3}$ This was confirmed by Morton and Chung's analysis of pedigrees published before 1959.24 More recently, however, Danielli et al ${ }^{16}$ obtained values between 0.1946 and 0.2931 in their extensive study of DMD families in Venetia, using the methods of Cheeseman et al. ${ }^{22}$ Similarly Bucher et $a l^{38}$ found $\mathrm{x}$ to be $0 \cdot 17$ (SE $0 \cdot 084$ ), significantly less than 0.33 at the $5 \%$ level, by segregation analysis of pedigrees of 55 families of DMD boys collected at the University of Iowa. Recent estimates, based on other carrier detection studies including lymphocyte capping, ${ }^{37}$ a technique recently validated by the methodological studies of Ho et al, ${ }^{51}$ and ribosomal protein synthesis, ${ }^{38}$ were comparable and similar to the values reported in our study.

The validity of our findings rests on the definition of an 'isolated case' and on whether the two clinical populations were representative of the general population of DMD families. Vogel ${ }^{31}$ suggested that accurate definition of the proportion of mutant cases in an $\mathrm{X}$ linked disease from genetic data required: complete ascertainment of all cases in a well-defined population over a certain period, confirmation of the clinical diagnosis by definitive laboratory tests, and personal examination of all available family members. No study of DMD has yet satisfied these stringent requirements but, while we did not attempt complete ascertainment in a geographical area (which has previously given variable results), the clinic families had been followed for many years and virtually all family members had been studied in depth, both clinically and biochemically, by the senior authors. Furthermore, the proportions of familial and non-familial cases in the two independent clinics was comparable to earlier population studies (table 1).

We considered any woman who had no family history of DMD at the time of birth of her first affected son to be the mother of an initially isolated case. Such mothers thus included homozygotes and carrier mothers of isolated (simplex) cases (together classed as possible carriers) and others who later had further affected sons (mothers of isolated multiplex sibships or probable carriers). This is of considerable practical importance. In our series, mothers of 17 such initially isolated cases had further affected sons. At present, secondary cases are nearly always born before the first affected boy is diagnosed, but if CK testing of newborn boys became routine, ${ }^{52} 53$ many of these secondary cases would be preventable, providing the correct risk of carrier status was assigned and appropriate counselling given. ${ }^{54}$ 
If, as we suggest, the proportion of new mutant cases is lower than believed, other sources of mutant genes or mechanisms for preserving genetic equilibrium must be invoked. Vogel and Rathenburg ${ }^{28}$ have reviewed the problem of mutation rate in man in detail. They calculated that an oocyte is derived from about 21 divisions of an ovarian stem cell while the average number of divisions which a male germ cell undergoes during a generation is some 10 to 20 times higher. This implies a much greater chance of genetic error since the mutation process is probably related to the number of DNA replications. The chance of error would be compounded by increasing age. Direct evidence of this is difficult to obtain but a 'paternal age effect', in which the father's age is greater than expected at the time of birth of an affected child, has been demonstrated in certain dominantly inherited conditions such as achondroplasia and Marfan's syndrome. A relatively increased mutation rate in males in $\mathrm{X}$ linked disorders is suggested by a maternal grandfather age effect, in which the maternal grandfather's age is greater than expected at the time of birth of the mother of the affected boy. This has been demonstrated in haemophilia $^{28}$ and Lesch-Nyhan disease. ${ }^{30}$ However, in DMD this effect is far from clear, ${ }^{55} 56$ although the recent study of Bucher et $a^{38}$ lent support to the thesis. Mothers might therefore be unwitting carriers as a result of mutation in previous generations in either the maternal or paternal lineage. A higher mutation rate in males than females is thus an attractive hypothesis but could not be confirmed in one recent study. ${ }^{57}$

Genetic equilibrium could theoretically also be maintained by heterozygote advantage. Danielli $e t$ $a l^{16}$ found that heterozygous women tended to have larger families than normal women. They also produced more carrier daughters than normal daughters, as determined by $\mathrm{CK}$ testing, and had more affected boys than normal boys, confirming earlier reports by Bundey and Edwards ${ }^{58}$ and more recently by Bucher et al. $^{38}$ However, it has been estimated that heterozygotes would have to be twice as fertile as normal women to maintain genetic equilibrium on this basis alone. This is unlikely, but heterozygote advantage could well provide a partial explanation for a high proportion of carrier mothers.

The possible influence of reproductive compensation in DMD should also be considered. While this can lead to an excess of heterozygotes if compensation is without regard to sex, if normal males are desired by even a small proportion of mothers with DMD boys, the predicted result would be a dramatic increase in the frequency of affected boys. ${ }^{59}$ Lange et $a l^{60}$ also noted that reproductive compensation was most likely to occur in diseases where there was an excessive loss of males in utero or early infancy, which is not a recognised characteristic of DMD families. However, we found that the ratio of male to female infant deaths was over three times higher in the three generations before ascertainment in our DMD families than in normal families over the same era, ${ }^{41}$ and Danielli et al ${ }^{16}$ recently reported a six-fold increase in perinatal mortality among males in their DMD families compared to the general population. Reproductive compensation may thus play a role of hitherto unsuspected importance in maintaining genetic equilibrium.

The data presented here add further support to the biochemical studies of DMD pedigrees previously reported from our laboratory, which suggested that nearly all mothers of DMD cases are heterozygotes. $^{33} 34$ Similar conclusions have been reached from carrier detection studies using lymphocyte capping techniques ${ }^{37} 51$ and protein synthesis by polyribosomes..$^{38}$ Our contention is not that sporadic cases never occur but that they are far less common than predicted in many genetic clinics.

We would like to thank Mr Bradley Metcalf for patiently collecting and documenting many of the pedigrees in the Duke series. We also thank Drs Robert Elston and Peggy Pericak-Vance of the Department of Genetics, University of North Carolina for helpful criticism and advice regarding problems of ascertainment. Thanks also to Drs Jeffery Vance and Nancy Mandell (Department of Medicine, Duke University), Dr Robin Winter (KennedyGalton Centre for Clinical Genetics, Hertfordshire), Professor Derek Roberts (Department of Medical Genetics, University of Newcastle upon Tyne), and Dr Judy Simpson (Department of Medical Statistics, University of Newcastle upon Tyne) for useful discussions on segregation analysis.

Dr Lane held a Muscular Dystrophy Association Clinical Research Fellowship. This work was supported in part by NINCDS grant NS13455, grant RR30 from the General Clinical Research Center's programme, and a Clinical Research Grant from the Muscular Dystrophy Association of America.

This work was presented in part at the annual meeting of the American Federation for Clinical Research, Washington, April 1979 and the Southern Society for Clinical Investigation, New Orleans, January 1980.

\footnotetext{
References

1 Haldane JBS. The rate of spontaneous mutation of a human gene. $J$ Genet 1935;31:317-26.

2 Davie AM, Emery AEH. Estimation of proportion of new
} 
mutants among cases of Duchenne muscular dystrophy. $J$ Med Genet 1978;15:249-53.

3 Stephens FE, Tyler FH. Studies in disorders of muscle. V. The inheritance of childhood progressive muscular dystrophy in 33 kindred. Am J Hum Genet 1951;3:111-25.

4 Stevenson AC. Muscular dystrophy in Northern Ireland. 1. An account of the condition in fifty-one families. Ann Hum Genet 1953;18:50-93.

5 Stevenson AC. Muscular dystrophy in Northern Ireland. 2. An account of nine additional families. Ann Hum Genet 1955;19:50-93.

- Stevenson AC. Muscular dystrophy in Northern Ireland. 4. Some additional data. Ann Hum Genet 1958;22:231-4.

7 Walton JN. On the inheritance of muscular dystrophy. Ann Hum Genet 1955;20:1-38.

8 Blyth A, Pugh RJ. Muscular dystrophy in childhood. The genetic aspect. Ann Hum Genet 1959;23:127-53.

9 Moser H, Weisman V, Richlerich R. Progressive muskel dystrophie. VI. Haüfigkeit, Klink und Genetik der Duchenne-form. Schweiz Med Wochenschr 1964;94: 1610-21.

10 Kuroiwa Y, Miyazaki T. Epidemiological study of myopathy in Japan. In: Milhorat AT, ed. Exploratory concepts in muscular dystrophy and related disorders. Amsterdam: Excerpta Medica, 1967;98-102.

11 Gardner-Medwin D. Mutation rate in the Duchenne type of muscular dystrophy. J Med Genet 1970;7:334-7.

12 Prot J. Genetic-epidemiological studies in progressive muscular dystrophy. J Med Genet 1971 ;8:90-6.

13 Lawrence EF, Brown B, Hopkins IJ. Pseudohypertrophic muscular dystrophy of childhood: an epidemiological survey in Victoria. Aust NZ J Med 1973;3:142-51.

14 Lubs ML. Haemophilia A and Duchenne muscular dystrophy in Colorado. Am J Hum Genet 1974;26:56A.

15 Brooks AP, Emery AEH. The incidence of Duchenne muscular dystrophy in the South-East of Scotland. Clin Genet 1977;11:290-4.

16 Danielli GA, Mostacciuolo ML, Pilotto H, Angelini C, Bonfante A. Duchenne muscular dystrophy. Data from family studies. Hum Genet 1980;54:63-8.

17 Kakulas BA, Hurse PV. Twelve years of genetic counselling in muscular dystrophy in Western Australia. Abstract No 303. IVth International Conference on Neuromuscular Diseases, Montreal, Canada, 1978.

18 Cowan J, Macdessi J, Stark A, Morgan G. Incidence of Duchenne muscular dystrophy in New South Wales and the Australian Capital Territory. J Med Genet 1980;17: 245-9.

19 Emery AEH, Morton R. Genetic counselling in lethal X-linked disorders. Acta Genet Statis Med 1968;18: 534-42.

20 Murphy EA, Mutalik GS. The application of Bayesian methods in genetic counselling. Hum Hered 1969;19: 126-51.

21 Emery AEH, Holloway S. Use of normal daughters' and sisters' creatine kinase levels in estimating heterozygosity in Duchenne muscular dystrophy. Hum Hered 1977; 27: 118-26.

22 Cheeseman EA, Kilpatrick SJ, Stevenson AC, Smith CAB. The sex ratio of mutation rates of sex-linked recessive genes in man, with particular reference to Duchenne-type muscular dystrophy. Ann Hum Genet $1958 ; 22: 235-43$.

${ }^{23}$ Smith CAB, Kilpatrick'SJ. Estimation of the sex ratio of mutation rates in the sex-linked conditions by the method of maximum likelihood. Ann Hum Genet 1958;22: 244-9.

24 Morton NE, Chung CS. Formal genetics of muscular dystrophy. Am J Hum Genet 1959;11:360-79.
25 Zatz M, Frota-Pessoa O, Levy JA, Peres CA. Creatine phosphokinase activity in relatives of patients with X-linked muscular dystrophies: a Brazilian study. J Genet Hum 1976;24:153-68.

26 Caskey CT, Nussbaum RL, Cohen LC, Pollack L. Sporadic occurrence of Duchenne muscular dystrophy: evidence for new mutation. Clin Genet 1980;18:329-41.

27 Bundey S. Calculation of genetic risks in Duchenne muscular dystrophy by geneticists in the United Kingdom. $J$ Med Genet 1978;15:249-53.

28 Vogel F, Rathenberg R. Spontaneous mutation in man. Adv Hum Genet 1975;5:223-318.

29 Biggs R, Rizza CR. The sporadic case of haemophilia A. Lancet 1976;ii:431-3.

30 Franke V, Felsenstein J, Cartler SM, et al. The occurrence of new mutants in the X-linked recessive Lesch-Nyhan disease. Am J Hum Genet 1976;28:123-7.

31 Vogel F. A probable sex difference in some mutation rates. Am J Hum Genet 1977;29:312-9.

32 Graham JB. Genotype assignment (carrier detection) in the haemophiliacs. Clin Haematol 1979;8:115-45.

33 Roses AD, Roses MS, Miller SE, Hull KL, Appel SH. Carrier detection in Duchenne muscular dystrophy. N Engl J Med 1976;294:193-8.

34 Roses AD, Roses MS, Metcalf BS, et al. Pedigree testing in Duchenne muscular dystrophy. Ann Neurol 1977;2: 271-8.

35 Radu H, Migea S, Torok Z, Bordeianu L, Radu A. Carrier detection in Duchenne type muscular dystrophy. A pluri-dimensional study. J Neurol Sci 1967;6:289-300.

36 Hausmanowa-Petrusewicz I, Niebroj-Dobosz I, Borkowska J, Lukasik E, Liszewska-Pfejfer D. Carrier detection in Duchenne muscular dystrophy. In: Rowland LP, ed. Pathogenesis of human muscular dystrophies. Amsterdam: Excerpta Medica, 1977;34-41.

37 Pickard NA, Greuner HD, Verrill HL, et al. Systemic membrane defect in the proximal muscular dystrophies. N Engl J Med 1978;299:841-6.

38 Bucher K, Ionasescu V, Hanson J. Frequency of new mutants among boys with Duchenne muscular dystrophy. Am J Med Genet 1980;7:27-46.

${ }^{39}$ Haldane JBS. Mutation in the sex-linked recessive type of muscular dystrophy. A possible sex difference. Ann Hum Genet 1956;20:344-7.

40 Skolnick M, Carmelli D, Tyler FH. A two locus selection hypothesis for Duchenne muscular dystrophy. Theor Popul Biol 1977;12:230-45.

41 Lane RJM, Roses AD. Analysis of pedigrees of isolated cases of Duchenne muscular dystrophy. Clin Res $1979 ; 27$ 375A.

42 Lane RJM, Roses AD, Robinow M. Segregation analysis in sibs born subsequent to first affected boys in families of isolated cases of Duchenne muscular dystrophy (DMD): implications for carrier risk assessment. In: Angelini C, Danielli GA, Fontanare D, eds. Muscular dystrophy N research advances and new trends. Amsterdam: Excerpta Medica, 1980:282-3.

43 Thompson MW, Murphy EG, McAlpine PJ. An assess- Nิ ment of the creatine kinase test in the detection of carriers $\omega$ of Duchenne muscular dystrophy. J Pediatr 1967;71: 82-93.

44 Roses MS, Nicholson MT, Kircher CS, Roses AD. Evaluation and detection of Duchenne's and Becker's $\mathscr{S}$ muscular dystrophy carriers by manual muscle testing. ? Neurology (Minneap) 1978;27:20-5.

45 Lane RJM, Gardner-Medwin D, Roses AD. Electrocardiographic abnormalities in carriers of Duchenne muscular dystrophy. Neurology 1980;30:497-501.

46 Roses AD, Shile PE, Herbstreith MH, Balakrishnan CV. 
Identification of abnormally [ $\left.{ }^{32} \mathrm{P}\right]-$ phosphorylated cyanogen bromide cleavage products in erythrocyte membrane spectrum in Duchenne muscular dystrophy. Neurology (Minneap) $1981 ; 31: 1026-30$.

47 Mabry ME, Roses AD. Increased [ $\left.{ }^{32} \mathrm{P}\right]$-phosphorylation of tryptic peptides of erythrocyte spectrum in Duchenne muscular dystrophy. Muscle and Nerve $1981 ; 4: 489-93$.

48 Meltzer HY, Domes E, Greenhaus L, Davis JM, Belmaker R. Genetic control of human plasma creatine phospholinase activity. Clin Genet 1978;13:321-6.

49 Sibert JR, Harper PS, Thompson RJ, Newcombe RG. Carrier detection in Duchenne muscular dystrophy. Evidence from a study of obligatory carriers and mothers of isolated cases. Arch Dis Child 1979;54:534-7.

50 Nicholson GA, Lane RJM, Gardner-Medwin D, Walton JN. Carrier testing in families of isolated cases of Duchenne muscular dystrophy; creatine kinase activities in female relatives of mothers with normal CK activity. J Neurol Sci $1981 ; 51: 29-42$.

51 Ho AD, Reitter B, Stojakowitz S, Fiehn W, Weisser J. Capping of lymphocytes for carrier detection in Duchenne muscular dystrophy: technical problems and a review of the literature. Eur J Pediatr 1980;134:211-6.

52 Zellweger H, Antonik A. Newborn screening for Duchenne muscular dystrophy. Pediatrics 1975;55:30-4.

53 Drummond LM. Creatine phosphokinase levels in the newborn and their use in screening for Duchenne muscular dystrophy. Arch Dis Child 1979;54:362-6.

54 Roses AD, Nicholson GA, Roe CR. Screening for Duchenne muscular dystrophy. Pediatrics 1977;60:248-51.

55 Hutton EM, Thompson MW. Parental age and mutation rate in Duchenne muscular dystrophy. Am J Hum Genet 1970;22:26A.

56 Emery AEH. Genetic considerations in the X-linked muscular dystrophies. In: Rowland LP, ed. Pathogenesis of human muscular dystrophies. Amsterdam: Excerpta Medica, 1976;42-52.

57 Yasuda N, Kondo $\mathrm{K}$. No sex difference in mutation rates of Duchenne muscular dystrophy. $\mathrm{J}$ Med Genet 1980;17:106-11.

58 Bundey S, Edwards JH. Genetic studies in Duchenne muscular dystrophy. Heredity 1978;40:325.

59 Templeton AR, Yokoyama S. Effect of reproductive compensation and the desire to have male offspring on the incidence of a sex-linked lethal disease. Am J Hum Genet 1980;32:575-81.

${ }^{60}$ Lange K, Gladstein K, Zatz M. Effects of reproductive compensation and genetic drift on X-linked lethals. Am J Hum Genet 1978;30:180-9.

Requests for reprints to Dr R J M Lane, Regional Neurological Centre, Newcastle General Hospital, Westgate Road, Newcastle upon Tyne NE4 6BE.
APPENDIX Estimation of proportion of new mutant cases.

Cheeseman et al ${ }^{22}$ (method B) reasoned that, given $n_{s}$ fraternities of $s$ sons of mothers of DMD boys, if $\mathrm{m}^{\prime}$ was the number of hereditary fraternities, then $\left(n_{s}-m_{s}^{\prime}\right)$ would be the number of fraternities of new mutant cases. If there were $a_{s}$ affected persons in fraternities of size $s$, the proportion of new mutant cases $\mathrm{x}$ would be

$$
\Sigma\left(n_{s}-m_{s}^{\prime}\right) / \Sigma a_{s} .
$$

In the hereditary fraternities with at least one affected member, the probability of observing exactly one affected would be

$$
\mathrm{s} /\left(2^{\mathrm{s}}-1\right)=\mathrm{p}_{\mathrm{s}}
$$

Therefore, if we observed $m_{s}$ fraternities in which more than one boy was affected then

$$
\mathrm{m}_{\mathrm{s}}^{\prime}=\mathrm{m}_{\mathrm{s}}\left(1-\mathrm{p}_{\mathrm{s}}\right) \text {. }
$$

An estimate of the proportion of new mutant cases is then

$$
\Sigma\left(\mathrm{n}_{\mathrm{s}}-\mathrm{m}_{\mathrm{s}}\left(1-\mathrm{p}_{\mathrm{s}}\right)^{-1}\right) / \Sigma \mathrm{a}_{\mathrm{s}} .
$$

The variance of $x$ is

$$
\operatorname{Var} \mathrm{x}=\mathrm{A}^{-2}\left[\operatorname{var} \mathrm{M}+\mathrm{x}^{2} \operatorname{var} \mathrm{A}+2 \mathrm{x} \operatorname{cov}(\mathrm{A}, \mathrm{M})\right]
$$

where $M$ is the total number of affected in hereditary fraternities, A the total number of affected subjects, and where

$$
\begin{aligned}
& \operatorname{var} M=\Sigma \frac{\mathrm{n}_{\mathrm{s}}}{\left(1-\mathrm{p}_{\mathrm{s}}\right)^{2}}\left\{\frac{\gamma_{\mathrm{s}}}{\eta_{\mathrm{s}}}\left(1-\frac{\gamma_{\mathrm{s}}}{\eta_{\mathrm{s}}}\right)\right\} \\
& \operatorname{var} \mathrm{A}=\Sigma \mathrm{n}_{\mathrm{s}}\left\{\frac{\mathrm{x}+(1-\mathrm{x})(\mathrm{s}+1) 2^{-1}}{\eta_{\mathrm{s}}}-\frac{1}{\eta_{\mathrm{s}}^{2}}\right\} \\
& \operatorname{cov}(\mathrm{AM})=\Sigma \frac{\mathrm{n}_{\mathrm{s}}}{\left(1-\mathrm{p}_{\mathrm{s}}\right)}\left\{\gamma_{\mathrm{s}}\left(\frac{1}{\eta_{\mathrm{s}}}-\frac{1}{\eta_{\mathrm{s}}}\right)\right.
\end{aligned}
$$

and

$\gamma_{s}=\left\{x+(1-x) 2^{1-s}\right\}, \eta_{s}=\left\{x+(1-x)\left(1-2^{-s}\right) 2 s^{-1}\right\}$. 